\section{Other consequences of reduced duty hours}

Far more serious than the consequences of mandated reductions in resident duty hours outlined by Pattani and colleagues ${ }^{1}$ is "the trend toward increased failure rates on the oral component of (American) surgical board examinations." Ahmed and colleagues ${ }^{2}$ report the failure rates for thoracic surgery tripling and general surgery doubling during the time period that the Accreditation Council for Graduate Medical Education mandated reductions in resident duty hours. They describe how surgical fellows are "inadequately prepared" for the operating room. If they weren't fellows, these surgeons would be practising in the community.

Surgical residents are doing fewer cases, especially emergency cases, and are less able to recognize and manage complications. The authors ${ }^{1}$ describe how patient safety may be compromised as these trainees lose valuable experience, but far more worrisome is that they may be incompetent despite completing their residency. This has the potential to be a long-term threat to the wellbeing of the patient population.

The results in Ahmed and colleagues' ${ }^{2}$ paper also question one of the "principles of a pan-Canadian response" to duty hours by describing how the "night float" system is far more disruptive to resident wellbeing than the traditional 24-hour call period. I hope the National Steering Committee on Resident Duty Hours will study this systematic review very closely before making any changes in Canada.

\section{Gregory C. Allen MD}

Providence St. Peter Hospital, Olympia, Wash.

\section{References}

1. Pattani R, Wu PE, Dhalla IA. Resident duty hours in Canada: past, present and future. CMAJ 2014; 186:761-5.

2. Ahmed N, Devitt KS, Keshet I, et al. A systematic review of the effects of resident duty hour restrictions in surgery: impact on resident wellness, training, and patient outcomes. Ann Surg 2014; 259:1041-53.

\section{The authors respond}

As we noted in our paper, ${ }^{1}$ reduced duty hours may negatively affect the development of competence, which could have an impact on patient safety. This is particularly relevant for procedure-intensive specialties, where increasing evidence suggests that workhour reforms have deleterious effects on educational outcomes, ${ }^{2-5}$ including worse scores on licensing examinations. ${ }^{6}$ The review by Ahmed and colleagues, ${ }^{7}$ which was published after our paper, came to similar conclusions.

We agree with Dr. Allen ${ }^{8}$ that it will be important for the educational community to consider these findings and others as they evaluate duty-hour reforms.

\section{Reena Pattani MD, Peter E. Wu MD,} Irfan A. Dhalla MD MSc

Department of Medicine (Pattani, Dhalla), St. Michael's Hospital; Department of Medicine, (Pattani, Wu, Dhalla), University of Toronto; Department of Medicine (Wu), Toronto General Hospital; Institute of Health Policy, Management and Evaluation (Dhalla), University of Toronto, Toronto, Ont.

\section{References}

1. Pattani R, Wu PE, Dhalla IA. Resident duty hours in Canada: past, present and future. CMAJ 2014;186:761-5

2. Poulose BK, Ray WA, Arbogast PG, et al. Resident work hour limits and patient safety. Ann Surg 2005;241:847-56

3. Hoh BL, Neal D, Kleinhenz D, et al. Higher complications and no improvement in mortality in the ACGME resident duty-hour restriction era: an analysis of more than 107,000 neurosurgical trauma patients in the Nationwide Inpatient Sample database. Neurosurgery 2012;70:1369-81.

4. Gopaldas RR, Chu D, Dao T, et al. Impact of ACGME work-hour restrictions on the outcomes of coronary artery bypass grafting in a cohort of 600,000 patients. J Surg Res 2010;163:201-9.

5. Breen KJ, Hogan A, Mealy K. The detrimental impact of the implementation of the European working time directive (EWTD) on surgical senior house officer (SHO) operative experience. Ir J Med Sci 2013:182:383-7.

6. Jagannathan J, Vates G, Pouratian N, et al. Impact of the Accreditation Council for Graduate Medical Education work-hour regulations on neurosurgical resident education and productivity. $\mathrm{J} \mathrm{Neu}$ rosurg 2009;110:820-7.

7. Ahmed N, Devitt KS, Keshet I, et al. A systematic review of the effects of resident duty hour restrictions in surgery: Impact on resident wellness, training, and patient outcomes. Ann Surg 2014:259:1041-53

8. Allan GC. Other consequences of reduced duty hours [letter]. CMAJ 2014;187:207.

CMAJ 2015. DOI:10.1503/cmaj.115-0007

\section{Medical tourism dialogue needs a broader scope}

We read Stanbrook and Fletcher's editorial ${ }^{1}$ with great interest. As the editorial argues, the decision for Canadian hospitals to treat international medical tourists should not be taken lightly. Treating private international patients in Canadian public hospitals may result in negative health-equity implications for Canadian patients.

Medical tourism is a global practice that also involves Canadian patients travelling to other countries for medical care. It must be acknowledged that the impact of inbound medical tourism to Canada, which you identify in your editorial, also holds true for many of the host of countries to which Canadian patients travel.

We call for dialogue among Canadian medical and health-professional groups about medical tourism. These groups must consider the implications for their members of Canadian patients' involvement in medical tourism. Speaking up only about international patients coming to Canada is to ignore the full scope and health-equity impact of this global health services practice.

Valorie A. Crooks PhD, Jeremy Snyder PhD

Simon Fraser University, Burnaby, BC

\section{Reference}

1. Stanbrook M, Fletcher J. Attracting medical tourists to Canada is a risky experiment. CMAJ 2014;186:971.

CMAJ 2015. DOI:10.1503/cmaj.115-0008

\section{Canada must help the wounded children of Gaza}

Stanbrook ${ }^{1}$ brings attention to a distressing situation in his editorial regarding the plight of wounded children in Gaza. ${ }^{1}$

All agree that the injuries to children in Gaza are a tragedy and that these injuries require treatment. What is even more tragic, however, is that these injuries and deaths can be prevented. At an 
address at the Ritz-Carlton Hotel in Toronto, Oct. 19, 2014, retired Harvard University law professor Alan Dershowitz stated:

Hamas uses children and women as human shields. Hamas leaders will brag about this and the media runs after the dead babies, counts the bodies even though every single [civilian] death [in this summer's war between Israel and Hamas] could have been prevented by Hamas. Canada is the only country in the world that understands with great moral clarity the difference between Hamas and Israel for seeing moral clarity while others see moral ambiguity.

Perhaps Canada's greatest contribution is our insight into the complexities of this disastrous situation and the exercise of moral, political and economic suasion applied to the parties concerned as well as the world community.

\section{Michael G. Sanders MD}

(Retired gastroenterologist), Toronto, Ont.

\section{Reference}

1. Stanbrook MB. Canada Must help the wounded children of Gaza. CMAJ 2014;186:1123.

CMAJ 2015. DOI:10.1503/cmaj.115-0009

\section{Management of a 28-year- old with chest pain}

The presumed goal of CMAJ's Practice section is primarily education. In this regard, Kennedy and colleagues' ${ }^{1}$ article was informative with respect to pericarditis but not with respect to the management of a 28-year-old with chest pain.

Indeed, it is both discouraging and disappointing that no mention is made of acute aortic dissection; discouraging since the message about this common and lethal diagnosis seems not to be understood despite the efforts of the Canadian Medical Protective Association and disappointing since the article was apparently peer reviewed.

Neil McKenzie MB ChB MD

London Helath Sciences Centre, London, Ont.

\section{Reference}

1. Kennedy SA, Singh SM. A 28-year-old man with acute chest pain. CMAJ. 2014;186:1161-2.

CMAJ 2015. DOI:10.1503/cmaj.115-0010

\section{The authors respond}

We thank McKenzie ${ }^{1}$ for his interest in our work. Indeed, acute aortic dissection should be considered in all individuals presenting with chest pain. A summary of Canadian Medical Protective Association data from 1991-2005 of patients with proven aortic dissection where medicolegal difficulties arose found that $44 \%$ of patients had pleuritic or positional chest pain, and a presumptive diagnosis of pericarditis was made in $12 \%$ of these patients. ${ }^{2}$ As the diagnosis of aortic dissection may elude even the most experienced clinician, it is important to maintain this on one's differential diagnosis and ensure that appropriate investigations and a treatment plan are instituted to address this diagnostic possibility. This is especially important because aortic dissection may masquerade as other common clinical conditions.

Sean A. Kennedy, Sheldon M. Singh MD School of Medicine (Kennedy), McMaster University, Hamilton, Ont.; Schulich Heart Centre (Singh), Sunnybrook Health Sciences Centre, University of Toronto, Toronto, Ont.

\section{References}

1. McKenzie N. Management of a 28-year-old with chest pain [letter]. CMAJ 2014;187:208

2. Aortic dissections: "Tearing" apart the data." Ottawa: The Canadian Medical Protective Association; 2008. Available: https://oplfrpd5.cmpa-acpm .ca/-/aortic-dissections-tearing-apart-the-data (accessed 2014 Oct. 25, 2014).

CMAJ 2015. DOI:10.1503/cmaj.115-0011

\section{Hepatitis C screening}

In a $C M A J$ news article, Fralick ${ }^{1}$ reports that it is unclear how Canadian hepatologists, who can barely manage their current caseloads, will be able to meet the inevitable increased demand for care created by wider screening.

Project ECHO (Extension for Community Healthcare Outcomes) was developed in 2003 by Dr. Sanjeev Arora, a hepatologist at the University of New Mexico, in Albuquerque, to address this problem via weekly video clinics with widely dispersed primary care providers. Case discussions and didactic lectures support the provision of evidence-based treatments in patients' hometowns.
This learning-by-doing model led to an increase in the number of patients in New Mexico who were cured of hepatitis C. Clinical outcomes of patients treated in the community matched those outcomes achieved in the University setting. ${ }^{2}$ Those cured of hepatitis $\mathrm{C}$ have been shown to have had a $93 \%$ reduction in liver-related mortality and a $74 \%$ reduction in 10-year all-cause mortality. ${ }^{3}$ Liver cancer rates declined by $76 \% .^{3}$ Effective treatment results in a reduction in costly liver transplants and management of liver cancer.

Access to treatments for addiction has increased via the Integrated Addictions and Psychiatry TeleECHO Clinic. ECHO-linked primary care providers offer vaccination for hepatitis A and B and education on prevention, alcohol cessation, hepatotoxic drug avoidance and nicotine and marijuana cessation to reduce rates of liver fibrosis.

By providing primary care providers with the skills and the support to practise at the highest level of their competence, ECHO can redress geographic imbalances in access to specialist care. The ECHO model also leads to rapid dissemination of best practices, increased primary care provider satisfaction and self-efficacy in managing complex chronic diseases, and improved patient outcomes. ${ }^{4}$

Ruth E. Dubin MD PhD, Andrea Furlan MD PhD, Sanjeev Arora MD

Department of Medicine (Dubin), Queen's University, Kingston, Ont.; Department of Medicine (Furlan), University of Toronto, Toronto, Ont.; ECHO Institute (Arora), University of New Mexico School of Medicine, Albuquerque, NM

\section{References}

1. Fralick M. Screening urged for hepatitis $\mathrm{C}$ but drug costs are prohibitive. CMAJ 2014;186:329.

2. Arora S, Thornton K, Murata G, et al. Outcomes of treatment for hepatitis $\mathrm{C}$ virus infection by primary care providers. N Engl J Med 2011;364:2199-207.

3. van der Meer AJ, Veldt BJ, Feld JJ, et al. Association between sustained virological response and all-cause mortality among patients with chronic hepatitis $\mathrm{C}$ and advanced hepatic fibrosis. JAMA 2012;308:2584-93.

4. Arora S, Kalishman S, Dion D, et al. QUALITY PROFILE: Partnering urban academic medical centers and rural primary care clinicians to provide complex chronic disease care. Health Aff 2011;30:1176-84.

CMAJ 2015. DOI:10.1503/cmaj. 115-0012 